\title{
Retrograt intrarenal cerrahi geriatrik erkek hastalarda böbrek taşı tedavisinde etkin ve güvenilir bir seçenek midir?
}

\section{Retrograt intrarenal cerrahi geriatrik erkek hastalarda böbrek taşı tedavisinde etkin ve güvenilir bir seçenek midir?}

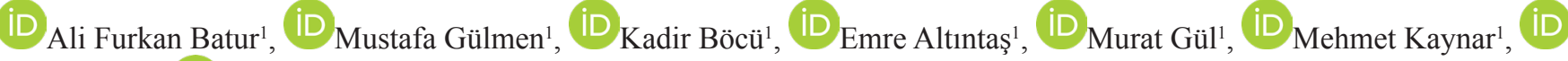
Özcan Kılıç ${ }^{1}$, iD Serdar Göktaş ${ }^{1}$.

${ }^{1}$ Selçuk Üniversitesi Tıp Fakültesi Üroloji Anabilim Dalı, Konya, Türkiye

$\ddot{O} z$

Amaç: Bu çalışmada böbrek taşı tedavisi için kliniğimizde retrograt intrarenal cerrahi(RİRC) uygulanılan geriatrik yaş grubu erkek hastaların etkinlik ve güvenlik sonuçlarının, daha genç yaş hasta grubu ile karşılaştırılarak sunulması amaçlanmıştır.

Gereç ve Yöntem: Kliniğimizde böbrek taşı nedeniyle RİRC uygulanmış olan, 40 yaş üzeri erkek hastaların verileri retrospektif olarak değerlendirildi. Hastalar yaşlarına göre iki gruba ayrıldı: 40-64 yaş (Grup 1) ve 65 yaş ve üzeri (Grup 2). Komorbidite değerlendirilmesi için anestezi risk skoru (ASA) ve modifiye Charlson komorbidite indeksi (MCKI) kullanıldı. Hastanenin kayıt sisteminden ve hastaların dosyalarından genel bilgiler, komplikasyon bilgileri, renal anormallik varlığı, taşın bulunduğu böbrek ve lokalizasyonu, taşın dansitesi, taşın boyutu, taş sayısı verileri ve postoperatif taş temizlenme verileri elde edildi.

Bulgular: Çalışmaya 233 tanesi Grup 1 (40-64 yaş) ve 61 tanesi Grup 2 (65 yaş ve üstü) olmak üzere toplam 294 hasta alınmıştır. ASA ve MCKİ skorları bakımından Grup 2'de yer alan hastaların skorları Grup 1'e göre istatistiksel olarak anlamlı olarak daha yüksek olarak bulunmuştur (sırasıyla p<0.001, p $<0.001$ ). Gruplar arasında taş dansitesi, taş boyutu, taş hacmi, operasyon süresi, hastanede yatış süreleri ve postoperatif taşsızlık oranları bakımından fark bulunmamıştır. Grup 1'de toplam 25 (\%10.7) hastada ve Grup 2'de toplam $10(\% 16.4)$ hastada komplikasyon geliştiği tespit edilmiştir ve gruplar arasında genel komplikasyon oranları açısından istatistiki fark bulunmamıştır $(\mathrm{p}=.265)$.

Sonuç: Dünya nüfusunun giderek yaşlanması ile beraber bu hasta grubunun hastalıklarının da en uygun tedavi metodlarıyla tedavi edilmesinin önemi artmıştır. Çalışmamızda RIRC yöntemi ile böbrek taşı tedavisi yaşlı hasta grubunda da güvenli ve etkili olarak çıkmıştır.

Anahtar kelimeler: Böbrek taşı, Komplikasyon, Geriatrik hasta, Retrograt intrarenal cerrahi, Komorbidite

Abstract

Objective: In this study, it was aimed to present the efficacy and safety results of geriatric male patients who underwent retrograde intrarenal surgery (RIRC) in our clinic for the treatment of kidney stones, by comparing them with the younger age group.

Material and Methods: The data of male patients over 40 years of age who underwent RIRC for kidney stones in our clinic were evaluated retrospectively. The patients were divided into two groups according to their age: 40-64 years (Group 1) and 65 years and older (Group 2). The data on the comorbidity status of the patients were compiled from their files. American Society of Anesthesiologists score(ASA) and modified Charlson comorbidity index(MCCI) were used for comorbidity assessment. General information, complication information, presence of renal abnormality, kidney and location of the stone, density of the stone, size of the stone, number of stones and postoperative stone clearance data were obtained from the hospital's registry system and the files of the patients.

Results: A total of 294 patients were included in the study, of which 233 were in Group 1 (40-64 years old) and 61 in Group 2 (65 years and older). In terms of ASA and MCKI scores, the scores of the patients in Group 2 were found to be statistically significantly higher than Group 1 ( $p<0.001$, $p<0.001$, respectively). There was no difference between the groups in terms of preoperative DJ catheter set, presence of renal abnormalities and non-functioning kidneys. There was no difference between the groups in terms of stone density, stone size, stone volume, operation time, hospital stay, and postoperative stone-free rates. Complications were detected in 25 (10.7\%) patients in Group 1 and in 10 (16.4\%) patients in Group 2, and there was no statistical difference between the groups in terms of overall complication rates ( $\mathrm{p}=.265)$.

Conclusion: With the aging of the world population, the importance of treating the diseases of this patient group with the most appropriate treatment methods has increased. In our study, kidney stone treatment with the RIRC method was found to be safe and effective in the elderly patient group.

Keywords: Kidney stone, Complication, Geriatric patient, Retrograde intrarenal surgery, Comorbidity

Yazışma Adresi: Ali Furkan Batur, Selçuk Üniversitesi Tıp Fakültesi Üroloji Anabilim Dalı, Konya, Türkiye

E-Posta: alifurkanbatur@gmail.com

Alınma tarihi: 16.07.2021 / Kabul tarihi: 23.08.2021 / Yayımlanma tarihi: 15.12.2021

Retrograt intrarenal cerrahi - Batur ve ark.

Genel Tip Derg 2021;31(4)396-401 
Böbrek taşları çok sık görülen, kişilerde ciddi morbiditelere neden olan ve ülkelerin sağlık harcamalarında önemli yer tutan patolojilerdir. Böbrek taşlarının tüm dünyada prevelansı tüm yaşlar dahil edildiğinde \%1 ile 8 arasında değişmektedir (1). İlk böbrek taş1 gelişimi erken yaşlarda olduğunda tekrarlama sıklığı artmaktadır. Bunun yanında böbrek taşlarının önemli bir kısmı da (\%1-20) 65 yaşından sonra görülmektedir (2).

Gelişen teknolojiye paralel olarak böbrek taşlarının son 30 yılda tedavisi minimal girişimsel yöntemlere doğru kaymıştır. Avrupa üroloji kılavuzları, büyüklüğü $2 \mathrm{~cm}$ 'e kadar olan böbrek taşlarının tedavisi için şok dalgaları vücut dışı ile taş kırma tedavisi(VD-TKT) ve retrograd intrarenal cerrahi(RİRC) yöntemlerini önermektedir (1). Ancak, son yıllarda bu 2cm'lik sınır özellikle RİRC yöntemi için zorlanmakta ve daha büyük taşlar da birden fazla seansta tedavi edilmektedir. VD-TKT, her ne kadar güvenli bir yöntem olarak tanımlansa da tekrarlayan tedavi seansları, kırılan taş parçalarının üreteri tıkayarak ağrıya ve acil cerrahi girişimlere neden olabilmesi, ultrasonik ses dalgalarının böbrekte yarattığı hasarlar ve kanamalar gibi bir takım dezavantajları bulunmaktadır (3).

Son 2 dekaddır böbrek taşı tedavisinde uygulanılan RİRC metodu teknolojik ekipmanların gelişmesi ile beraber sürekli gelişmeye devam etmiştir. Optik görüntüleme, ışık aktarımı ve taş kırma teknolojilerinde gerçekleşen gelişmeler sayesinde ve fleksible endoskop kalınlığının azaltılabilmesi sayesinde RİRC yöntemi ile hastalar çok daha az komplikasyonla tedavi edilebilir duruma gelmiştir (4). Ancak, bu yöntem ile de daha az sıklıkla da olsa kanama, geride taş kalması, üriner sistem enfeksiyonu, piyelonefrit ve ürosepsis gibi komplikasyonlar olabilmektedir. Ancak bu komplikasyonların oranları VD-TKT ve özellikle de perkütan nefrolitotomi(PNL) metodları ile karşılaştırıldığında çok daha kabul edilebilir seviyelerdedir $(5,6)$. PNL, 2cmden büyük böbrek taşlarının tedavisinde uygulanılan ve ehil ellerde etkinlik sonuçları oldukça iyi olan bir yöntemdir. Ancak, geriatrik hasta grubunda daha da fazla olmak üzere transfüzyon gerektiren kanama, iç organlarda hasarlar ve hidrotoraks gibi ciddi komplikasyonları bulunmaktadır $(7,8)$.

Yapılan çalışmalar dünya yaşlı nüfusunun hızla arttığını göstermektedir. Önemli epidemiyolojik bir çalışmaya göre 2050 yılında 60 yaş üzeri tahmini nüfus 2 milyarı geçecektir (9). Yaşlanan nüfusun ve endüstriyelleşme düzeyinin artması ve buna mukabil beslenme alışkanlıklarının değişmesi ile yaşlı nüfusta daha sıklıkla böbrek taşları görülmektedir. Yaş, tek başına bir hastalık olmamakla beraber, organ fonksiyon rezervlerinde azalmaya ikincil olarak perioperatif dönemde komplikasyonlar görülebilmektedir. Bunun yanında yaşın artması ile beraber sıklığı artan çeşitli komorbiditeler böbrek taşı tedavisi esnasında çeşitli komplikasyonların artışına neden olabilmektedir. Yaşlı nüfusta sıklığı artan komorbiditeler arasında koroner kalp hastalıkları, akciğer hastalıkları, hipertansiyon, diabetes mellitus ve nörolojik bozukluklar yer almaktadır (10). Bu nedenle geriatrik popülasyonda en güvenli ve etkili böbrek taşı tedavisi yöntemleri için ayrıntılı olarak çalışılmaktadır (10-12).

Biz de bu temel bilgilerden yola çıkarak bu çalışmada, kliniğimizde böbrek taşı tedavisi için RİRC uygulanmış olan geriatrik yaş grubu erkek hastalarımızın etkinlik ve güvenlik sonuçlarını daha genç yaş hasta grubumuz ile karşılaştırarak sunmayı ve irdelemeyi amaçladık.
Bu retrospektif dosya tarama çalışması, 1964 Helsinki Bildirgesi ve daha sonraki değişiklikleri veya karşılaştırılabilir etik standartlara uygun gerçekleştirildi. Çalışmaya başlamadan evvel çalışmaya üniversitemizin etik kurulu tarafından etik onay alındı.

Çalışma için kliniğimizde Ocak 2012-Mayıs 2021 tarihleri arasında RİRC uygulanılan 722 hastanın dosyaları tarand1. Bu hastalardan 286 tanesi kadın olduğu için çalışmadan çıkarıldı. Kalan 436 hastanın 117 tanesi 40 yaş altın olduğu için çalışmadan çıkarıldı. Sonuç olarak kalan 319 hastanın dosyaları incelendi. Bu hastaların 25 tanesi de görüntüleme, laboratuar ve takip eksikliğinden dolayı çalışma dışı bırakıldı. Sonuç olarak 294 hasta dahil edildi.

Hastaların verileri hasta dosyalarından ve hastane veri tabanından elde edildi. Hastalar 40-64 yaş (Grup 1) ile 65 yaş ve üstü (Grup 2) olmak üzere iki gruba ayrıldı. Hastaların dosyalarından yaş, boy, kilo, ek hastalık varlığı, anestezi risk skorları (American Society of Anesthesiologists-ASA) ve preoperatif ile postoperatif kan üre azotu (KÜA), kreatinin ve hemoglobin (HB) değerleri toplandı. Hastaların ek hastalıklarına göre modifiye Charlson komorbidite indeksi (MCKI) kullanılarak skorlaması yapıldı (13). Taş cerrahisi planlanan hastalara rutin olarak abdominal bilgisayarlı tomografi (BT) yapıldı ve BT görüntülerinden renal anormallik varlığı, taşın bulunduğu böbrek ve lokalizasyonu, taşın dansitesi, taşın boyutu ve taş sayısı verileri elde edildi. Hastaların ameliyat ve takip kayıtlarından operasyon süresi, taş temizlenme durumu, hastanede kalış süresi, tekrar yatış gereksinimi ve komplikasyon varlığı bilgileri edinildi. İntraoperatif ve postoperatif komplikasyonlar modifiye Clavien-Dindo sinıflandırma sistemi kullanılarak kayıt edildi (14)

Tüm hastalar, opere edilmeden önce rutin uygulama gereği ameliyat onam formlarını imzaladı. Üreteral darlık dolayısıyla üreterden giriş kılıfı yerleştirilememesine bağlı olarak taş tedavisinin birden fazla seansta tamamlanabileceği her hastaya anlatıldı ve bu konuda onamı alındı. Hastaların preoperatif dönemde idrar kültürleri değerlendirildi ve yalnızca idrarı steril olan hastalar opere edildi. Güncel kılavuzların önerisi doğrultusunda hastalara preoperatif dönemde (operasyon öncesi 30 dakika-1 saat arası) profilaktik intravenöz geniş spektrumlu antibiyotik uygulaması -rutin uygulama gereği- yapıldı. Tüm hastalara genel anestezi altında standart litotomi pozisyonunda $7.5 \mathrm{Fr}$ flexible üreteroskop (Karl Storz FLEX-X2, Tuttlingen, Almanya) ile RIRC uygulandı. Taşlar $272 \mu \mathrm{m}$ Holmium YAG lazer fiberi (Dornier Medilas H 20 Laser, Wessling, Almanya) ile kırıldı. Kliniğimizin RIRC yönteminde rutin uygulaması gereği her hastanın üreterine giriş kılıfi (9.5/11.5F, Cook Medical, Bloomington, ABD) yerleştirildi ve ameliyat bitiminde opere edilen tarafta böbreğe ve üretere double j (DJ) kateter (Cook Medical, Bloomington, ABD) yerleştirildi. Üreterine giriş kılıfı yerleştirilemeyen hastalara kılıf olmadan giriş yapılmadı ve DJ kateter takılarak pasif dilatasyona birakıldı. Bu hastalar 3 hafta sonra opere edildi. Hastaların taşlarının temizlendiği ve DJ kateterlerinin doğru şekilde yerleştirildiği C kollu skopi cihazı (ZEN-2090 Pro, Genoray.Co.Ltd, Gyeonggi-do, Kore) kullanılarak doğrulandı. Hastanede ek yatış gerektiren komplikasyonlar olmadığı sürece, hastalar postoperatif 1.gün taburcu edildi. Taşsızlık durumu postoperatif dönemde rutin olarak uygulanılan 1.ay kontrol abdominal BT ile belirlendi ve $3 \mathrm{~mm}$ ve altında taş kırıntıları olan hastalar taşsız olarak kabul edildi. Bu boyuttan daha büyük taşı olan hastalara ikinci bakış RİRC planlandı. 


\section{İstatistiksel Yöntem}

Tüm istatistiksel analizler, IBM Statistical Package for the Social Sciences sürüm 22 (IBM SPSS Statistics for Windows, Chicago, IL, ABD) kullanılarak yapıldı. Nicel değerler parametrik veriler için ortalama \pm standart sapma ile verilirken, parametrik olmayan veriler için değerler medyan [minimum-maksimum (min-maks)] ile verildi. Kategorik değişkenlerin verileri sayı ve yüzde olarak sunuldu. Değişkenlerin normalliğini kontrol etmek için Kolmogorov-Smirnov testi ve Q-Q grafikleri kullanıldı. Gruplar arasındaki parametrelerdeki farklılıkları değerlendirmek için bağımsız t testi, Mann-Whitney U testi ve ki-kare testi kullanıldı. Grupların kendi içlerinde ameliyat öncesi ve sonrası değerleri arasında ki farkın değerlendirilmesi için Wilcoxon testi kullanıldı. P değerinin 0.05 'ten küçük olması anlamlı olarak kabul edildi.

\section{Bulgular}

Yaşlarına göre hastaların 233 tanesi Grup 1 (40-64 yaş) ve 61 tanesi Grup 2 (65 yaş ve üstü) olarak sınıflandırılmıştır. Gruplar arasında vücut kitle indeksi bakımından anlamlı fark bulunmamıştır. Hastalar komorbiditelerine göre değerlendirildiğinde ASA ve MCKİ skorları bakımından yaşlı grupta yer alan hastaların skorları Grup 1'e göre istatistiksel olarak anlamlı olarak daha yüksek olarak bulunmuştur (sırasiyla $\mathrm{p}<0.001, \mathrm{p}<0.001$ ). Preoperatif DJ katater takımı, renal anormallik varlığı ve non-fonksiyone böbrek varlığı bakımından gruplar arasında fark bulunmamıştır (Tablo 1). Taş özellikleri ve süreler bakımından değerlendirildiğinde, gruplar arasında taş dansitesi, taş boyutu, taş hacmi, operasyon süresi ve hastanede yatış süreleri bakımından fark bulunmamıştır. Taşların lokasyonları değerlendirildiğinde her iki grupta da opere edilen taşların ağırlıklı olarak renal pelvis, alt kaliks ve birden fazla kaliks yerleşimli olduğu tespit edilmiştir. Taş lokasyonları bakımından da gruplar arasında fark bulunmamıştır. Gruplar arasında postoperatif taşsızlık oranları bakımından fark bulunmamıștır (Tablo 1). Grup 1 de opere edilen hastaların preop HB değerleri ortancası 15 iken postop HB ortancası 14.7 olarak bulunmuştur ve arada ki fark istatistiksel olarak anlamlı bulunmuştur ( $\mathrm{z}=-7.185, \mathrm{p}<0.001)$. Grup 1 içinde hastaların preoperatif ve postoperatif KÜA ve kreatinin değerleri arasında istatiksel anlamlı fark bulunmamıştır. Benzer şekilde, Grup 2 de opere edilen hastaların preop HB değerleri ortancası 14 iken postop HB ortancas1 13.2 olarak bulunmuştur ve arada ki fark istatistiksel olarak anlamlı bulunmuştur ( $\mathrm{z}=-2.989, \mathrm{p}=.003)$. Grup 2 içinde hastaların preoperatif ve postoperatif KÜA ve kreatinin değerleri arasında istatiksel anlamlı fark bulunmamıştır (Tablo 2).

Grup 1'de toplam 25 (\%10.7) hastada ve Grup 2'de toplam 10 (\%16.4) hastada komplikasyon geliştiği tespit edilmiştir ve gruplar arasında genel komplikasyon oranları açısından istatistiki fark bulunmamıştır $(\mathrm{p}=.265)$. Komplikasyonların ayrıntısı değerlendirildiğinde ClavienDindo sınıflamasına göre 2. derece ve üstü olarak sınıflandırılan komplikasyonlar Grup 1'de 10 (\%4.3) hastada Grup 2'de 8 (\%13.2) hastada tespit edilmiştir. Sadece komplikasyon olan vakalar dahil edilerek istatistik uygulandığında gruplar Clavien Dindo 1 ve Clavien Dindo 2 ve üstü komplikasyon varlığı bakımından karşılaştırıldığında arada ki fark istatistiksel olarak anlamlı bulunmuştur $(\mathrm{p}=.032)($ Resim 1). Grup 2'de tekrar hastaneye yatı̧ gereksinimi istatistiksel olarak anlamlı bir şekilde daha fazla bulunmuştur $(\mathrm{p}=.024)$. Komplikasyonlar ve hastaneye tekrar yatış gereksinimi ilgili bilgiler Tablo 3'de ayrıntılı olarak verilmiştir.
Tablo 1. Gruplara göre hastaların demografik ve tıbbi özellikleri

\begin{tabular}{|c|c|c|c|}
\hline Parametre & $\begin{array}{l}\text { Grup } 1(\mathrm{~N}=233) \\
\text { (64 yaş ve altı) }\end{array}$ & $\begin{array}{l}\text { Grup } 2(N=61) \\
\text { (65 yaş ve üstii) }\end{array}$ & p değeri \\
\hline VKİ Ortanca (Min-Max) & $26,730(18,6-42,9)$ & $25,763(20,1-36,8)$ & $.052^{\mathrm{a}}$ \\
\hline $\operatorname{ASA}(1 / 2 / 3 / 4) N$ & $25 / 193 / 15 / 0$ & $5 / 41 / 14 / 1$ & $<.001^{\mathrm{b}}$ \\
\hline MCKİ N(\%) & & & $<.001^{\mathrm{c}}$ \\
\hline $1-3$ & $194(\% 83.3)$ & $15(\% 24.6)$ & \\
\hline $4-6$ & $33(\% 14.2)$ & $33(\% 54.1)$ & \\
\hline $7-10$ & $6(\% 2.6)$ & $13(\% 21.3)$ & \\
\hline Preop dj N(\%) & & & $.524^{\mathrm{b}}$ \\
\hline Var & $175(\% 75.1)$ & $46(\% 75.4)$ & \\
\hline Yok & $57(\% 24.5)$ & $14(\% 23)$ & \\
\hline Nefrostomi tüpü & $1(\% 0.4)$ & $1(\% 1.6)$ & \\
\hline Renal anormallik $\mathrm{N}(\%)$ & & & $.505^{\mathrm{c}}$ \\
\hline Var & $26(\% 11.2)$ & $9(\% 14.8)$ & \\
\hline Yok & $207(\% 88.8)$ & $52(\% 85.2)$ & \\
\hline $\begin{array}{l}\text { Nonfonksiyone böbrek } \\
\mathrm{N}(\%)\end{array}$ & & & $.052^{\mathrm{c}}$ \\
\hline Var & $13(\% 5.6)$ & $8(\% 13.1)$ & \\
\hline Yok & $220(\% 94.4)$ & $53(\% 86.9)$ & \\
\hline Taraf N(\%) & & & $.227^{\mathrm{c}}$ \\
\hline Sağ & $98(\% 42.1)$ & $26(\% 42.6)$ & \\
\hline Sol & $124(\% 53.2)$ & $35(\% 57.4)$ & \\
\hline Bilateral & $11(\% 4.7)$ & 0 & \\
\hline Taş lokalizasyonu & & & $.838^{\mathrm{b}}$ \\
\hline ÜPB & $2(\% 0.9)$ & 0 & \\
\hline Pelvis & $80(\% 34.3)$ & $19(\% 31.1)$ & \\
\hline Alt kaliks & $69(\% 29.6)$ & $20(\% 32.8)$ & \\
\hline Orta kaliks & $17(\% 7.3)$ & $6(\% 9.8)$ & \\
\hline Üst kaliks & $4(\% 1.7)$ & $2(\% 3.3)$ & \\
\hline Multiple kaliks & $61(\% 26.2)$ & $14(\% 23)$ & \\
\hline Dansite (HÜ) & $1100(350-2050)$ & $1240(300-2034)$ & $.487^{\mathrm{a}}$ \\
\hline \multicolumn{4}{|l|}{ Ortanca(Min-Max) } \\
\hline Taş boyutu (mm) & $14(3-72)$ & $15(5-32)$ & $.576^{\mathrm{a}}$ \\
\hline \multicolumn{4}{|l|}{ Ortanca (Min-Max) } \\
\hline Taş volümü $\left(\mathrm{mm}^{3}\right)$ & $820(19-18900)$ & $1110(88-9800)$ & $.326^{\mathrm{a}}$ \\
\hline \multicolumn{4}{|l|}{ Ortanca (Min-Max) } \\
\hline Operasyon süresi (min) & $45(15-150)$ & $45(30-120)$ & $.393^{\mathrm{a}}$ \\
\hline \multicolumn{4}{|l|}{ Ortanca (Min-Max) } \\
\hline Taşsızlık N(\%) & $151(64.8 \%)$ & $33(54.1 \%)$ & $.138^{\mathrm{c}}$ \\
\hline $\begin{array}{l}\text { Hastanede kalış süresi } \\
\text { (gün) }\end{array}$ & $1(1-15)$ & $1(1-90)$ & $.122^{\mathrm{a}}$ \\
\hline
\end{tabular}

Ortanca(Min-Max)

VKİ vücut kitle indeksi, ASA American Society of Anesthesiologists(anestezi skoru), MCKI modified Charlson komorbidite indeksi, ÜPB üreteropelvik bileşke, Hü Hounsfield Ünitesi

${ }^{a}$ Mann-Whitney U testi, ${ }^{\mathrm{b}}$ Fisher Exact testi, ${ }^{\mathrm{c}}$ KiKare testi 
Tablo 2. Grupların kendi içerisinde preoperatif ve postoperatif hemoglobin, kreatinin ve kan üre azotu değerlerinin karşılaştırılması

\begin{tabular}{|l|l|l|l|}
\hline Gruplar ve Parametre & Preoperatif & Postoperatif & P değeri \\
\hline Grup 1 & & & \\
\hline Hemoglobin & $15(10.7-19.4)$ & $14.7(8.9-18.9)$ & $<.001$ \\
\hline Kreatinin & $0.92(0.55-2.17)$ & $0.92(0.7-3.1)$ & .350 \\
\hline Kan üre azotu & $33.6(8-76.8)$ & $32.9(12-82)$ & .439 \\
\hline & & & \\
\hline Grup 2 & & & .003 \\
\hline Hemoglobin & $14(7.2-16.4)$ & $13.2(8.5-16.1)$ & .118 \\
\hline Kreatinin & $1.14(0.7-3.1)$ & $1.09(0.7-2.89)$ & .641 \\
\hline Kan üre azotu & $40.1(17.4-103.2)$ & $43.7(23-85)$ & \\
\hline
\end{tabular}

*Wilcoxon testi kullanılmıştır

Tablo 3. Gruplara göre komplikasyonların ayrıntısı

\begin{tabular}{|c|c|c|c|}
\hline \multirow[t]{2}{*}{ Komplikasyon } & Grup $1(\mathrm{~N}=233)$ & Grup $2(\mathrm{~N}=61)$ & \multirow[t]{2}{*}{$\begin{array}{l}\mathbf{p} \\
\text { değeri }\end{array}$} \\
\hline & (64 yaş ve altı) & (65 yaş ve üstü) & \\
\hline Komplikasyon & & & $.265^{*}$ \\
\hline Var & $25(\% 10.7)$ & $10(\% 16.4)$ & \\
\hline Yok & $208(\% 89.3)$ & $51(\% 89.3)$ & \\
\hline Clavien Dindo Derece1 & $15(\% 6.4)$ & $2(\% 3.3)$ & \\
\hline Ateş & $8(\% 3.4)$ & $1(\% 1.6)$ & \\
\hline Renal Kolik & $3(\% 1.3)$ & - & \\
\hline Göğüs ağris1 & $2(\% 0.9)$ & $1(\% 1.6)$ & \\
\hline Hematüri & $2(\% 0.9)$ & - & \\
\hline Clavien Dindo Derece 2 & $6(\% 2.6)$ & $2(\% 3.3)$ & \\
\hline Postop ÜSE & $5(\% 2.1)$ & $2 \%(3.3)$ & \\
\hline Renal Kolik & $1(\% 0.4)$ & - & \\
\hline \multicolumn{4}{|c|}{ (Tekrar hastaneye yatış gerektiren) } \\
\hline Clavien Dindo Derece 3a & $1(\% 0.4)$ & - & \\
\hline \multicolumn{4}{|l|}{ Glob vezikale } \\
\hline Clavien Dindo Derece 3b & $2(\% 0.9)$ & $4(\% 6.6)$ & \\
\hline \multicolumn{4}{|l|}{ Taş yolu } \\
\hline \multicolumn{4}{|l|}{ (Üreterorenoskopi gerektiren) } \\
\hline Clavien Dindo Derece 4a & $1(\% 0.4)$ & $2(\% 3.3)$ & \\
\hline \multicolumn{4}{|l|}{ Sepsis (YBÜ yatı̧ gerektiren) } \\
\hline Tekrar hastaneye yatış & & & $.024^{*}$ \\
\hline Evet & $11(\% 4.7)$ & $8(\% 13.1)$ & \\
\hline Hayır & $222(\% 95.3)$ & $53(\% 86.9)$ & \\
\hline
\end{tabular}

ÜSE üriner sistem enfeksiyonu, YBÜ yoğun bakım ünitesi

*Ki-Kare testi

Genel Tip Derg 2021;31(4)396-401
Resim 1. Gruplandırılmış Clavien Dindo sınıflandırmasına göre komplikasyon oranlarının gruplar arasında karşılaştırılması

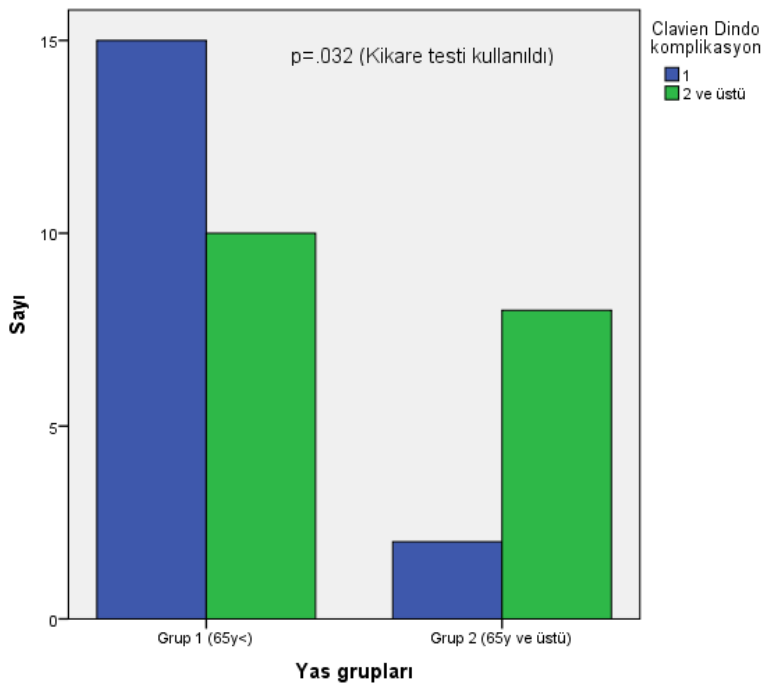

\section{Tartışma}

Demografik çalışmalar dünya nüfusunun yaşlandığını göstermektedir. Önemli bir prevelans çalışmasına göre 2050 yılında dünya nüfusunun \%21.1'i 60 yaş ve üzerinde olacaktır. Yine aynı çalışmada, gelişmiş ülkelerde beklenen ortalama yaşam süresi 83 'e ulaşacak ve daha az gelişmiş ülkelerde bu rakam 75'e çıkacaktır (15). Özellikle gelişmiş ülkelerde yaşlı hasta popülasyonunda struvit ve ürik asit taşları başta olmak üzere taş görülme sıklığı artmaktadır (2). Yaşlı popülasyonda komorbiditeler ve buna bağlı medikasyonlar artmaktadır. Bu hasta grubunda PNL'nin ciddi yan etkileri olması ve VD-TKT'nin etkinliğinin sınırlı olması sebebiyle göreceli olarak minimal invazif bir yöntem olan RİRC öne çıkan bir tedavi modalitesi haline gelmiştir. RİRC özellikle gebelik, obezite, koagülapati, iskelet deformiteleri, büyük kaliks taşları, kalisiyel divertiküller ve böbrek anomalileri durumlarında düşük komplikasyon ve yüksek başarı oranları ile de tercih edilen bir metoddur (16).

Çalışmamızda böbrek ve taş özellikleri gruplar arasında fark olmadığı çıkmıştır. Etkinlik sonuçları açısından değerlendirildiğinde, postoperatif ana başarı kriteri olan taşsızlık oranları bakımından yine gruplar birbirine benzer çıkmıştır. Komorbiditeler bakımından yaşlı grubun preoperatif komorbiditelerinin fazla çıkmış olması beklenen bir bulgudur. Ancak buna karşın gruplar arasında genel komplikasyon oranları açısından farklılık çıkmaması RİRC yönteminin geriatrik popülasyonda da böbrek taşı tedavisinde güvenilir bir şekilde uygulanabileceğini göstermiştir. Ancak, Clavien Dindo sınıflamasına göre 2.derece ve üstü komplikasyonların geriatrik yaş grubunda istatistiksel olarak anlamlı bir şekilde fazla çıkmış olması ve hastaneye tekrar yatış gereksinim oranlarının daha fazla olması, bu yaş grubunda yapılacak her türlü cerrahi müdahele gibi RİRC işleminin de uygulanması sürecinde çok dikkatli olunması gerektiğini göstermektedir.

Literatürde RİRC sonrası total komplikasyon oranları $\% 7$ ile \%16.3 arasında bildirilmiştir (10,17). Çalışmalar arasında komplikasyon oranlarının farklılık, komplikasyonların tanımlanmasında ki farklılıklar ve bazı çalışmalarda sadece cerrahiye ait komplikasyonların dahil edilip diğer medikal durumların 
komplikasyon olarak belirtilmemesinden ileri gelmektedir. RİRC sonrası en sık olarak görülen minör komplikasyonlar arasında ateş, hematüri, renal kolik ve üriner enfeksiyon yer almaktadır. Bazı çalışmalarda komplikasyon olarak dahil edilmeyen göğüs ağrısı, aritmi, dispepsi, respiratuar distres, geçici iskemik atak ve deliryum gelişimi gibi mevcut komorbiditelerin de etkisi ile postoperatif dönemde gelişebilen sistemik cerrahi komplikasyonları da bulunmaktadır. Major komplikasyon olarak septik şok ve buna bağ 1 ölüm RİRC sonrası nadiren de olsa görülebilmektedir. Berardinelli ve arkadaşlarının yayınlamış olduğu bir çalışmada 65 yaş altı ve üstü hastaların RİRC yöntemi ile tedavi sonuçları yayınlanmıştır. $\mathrm{Bu}$ çalışmaya göre karşılaştırılan grupların böbrek taşı özellikleri, operasyon ve hastanede kalış süreleri, komplikasyon oranları ve tekrar hastaneye yatırılma oranları benzer çıkmıştır. Bunun yanında 65 yaş üstü grupta taşların temizlenme oranları daha düşük bulunmuş olsa da bu fark istatistiksel olarak anlamlı bulunmamıştır (18). Geriatrik hasta popülasyonunda RİRC yönteminin etkinliğini ve güvenliğini değerlendiren bir diğer çalışmada Gökçen ve ark. 65 yaş üstü hastalarda taş temizlenme oranlarını \%81.4 olarak bulmuşken bu oran 65 yaş altı hastalarda \%91.8 olarak bulunmuştur. Aynı çalışmada minör komplikasyon oranları 65 yaş üstü ve altı hastalar için sırasıyla $\% 11.2$ ve \%3.2 olarak bulunmuș ve arada ki bu farkın istatistiksel olarak anlamlı olduğu belirtilmiştir (12). Aykaç ve arkadaşlarının çalışmasında sadece geriatrik hasta grubu değerlendirilmeye alınmış ve hastalar 65-74, 75-84 ve 84 ve üstü olmak üzere 3 gruba ayrılmışlardır. Bu çalışmanın sonuçlarında taş temizlenme oranları gruplar arasında farklı çıkmamıştır. Bu çalışmada hem cerrahi hem de medikal komplikasyonlar dahil edildiği için genel komplikasyon oranları literatüre göre göreceli olarak hafif fazla (\%16.3) olarak bulunmuş olsa da gruplar arasında komplikasyon oranları bakımında anlamlı fark bulunmamıştır (10).

Bizim çalışmamızda da taş özellikleri, operasyon süresi ve hastanede yatış süreleri bakımından fark bulunmamıştır. Beklendiği üzere ASA ve MCKİ skorlarına göre yaşlı grup daha fazla komorbiditeye sahip olarak bulunmuştur. Buna karşın RİRC sonrası genel komplikasyon oranları grup 1 için \%10.7 ve Grup 2 için \%16.4 olarak bulunmuştur. Ancak, bizim çalışmamızda da medikal durumlar da komplikasyon olarak değerlendirilmiştir. Hastalarımızda postoperatif dönemde en sık ateş görülmüştür. Bunun yanında idrar yolu enfeksiyonu ve renal kolik sık görülen komplikasyonlar olarak göze çarpmaktadır Grup 1'de 1 hastada sepsis durumu gelişmiş ancak hasta geniş spektrumlu intravenöz antibiyotik tedavisi ile tamamen iyileşmiştir. Yaşlı grupta, 2 hastada yoğun bakım yatışı gereksinimi (respiratuar distres nedeniyle) olmuş ancak bu hastalar da tamamen iyileşmiştir. Hastalarımızda genel komplikasyon oranları arasında ki fark istatistiksel olarak anlamlı bulunmamışken, Clavien Dindo 2 ve üstü komplikasyon oranı yaşı hasta grubunda daha fazla çıkmıştır. Buna ikincil hastaneye tekrar yatırılma oranları da grup 2'de daha fazla çıkmıştır. Bunların yanında etkinlik sonuçları bakımından değerlendirildiğinde postoperatif taşsızlık oranları bakımından gruplar arasında fark olmadığı görülmüştür. Çalışmamızda hastaların postoperatif taşsızlık oranları literatürle uyumlu olarak bulunmuştur.

Bu çalı̧̧manın belki de en önemli sınırlaması retrospektif oluşudur. Hastalarımızın daha spesifik bir grup olması adına sadece erkek popülasyondan oluşturulması bir sınırlama olarak değerlendirilebilir. Cerrahi ve medikal tüm komplikasyonların Clavien-Dindo sınıflamasına göre değerlendirilerek dahil edilmesi çalışmanın güçlü yanlarından bir tanesidir. Taş özellikleri bakımından gruplar arasında istatistiksel farkın çıkmamış olması değerlendirmeye alınan hasta grubunun heterojenliğini yansıtması bakımından önemlidir.

\section{Sonuç}

Çalışmamız neticesinde RİRC ile böbrek taşı tedavisi yaşlı hasta grubunda da etkili ve güvenli bir seçenek olarak çıkmıştır. Yaşlanma ile beraber komorbiditeler artmış olsa da komplikasyon oranları arasında ciddi bir fark bulunmamıştır. Bunun yanında postoperatif en önemli başarı kriteri olan taşsızlık oranları da preoperatif taş özellikleri birbirine çok yakın olan gruplar arasında farklı çıkmamıştır. Yine de preoperatif dönemde komorbiditeleri fazla olan yaşlı grup hastalarda çok dikkatli ve titiz bir değerlendirme yapılması ve postoperatif dönemde de hastaların yakın takip edilmesi bu hasta grubunda da taş tedavisinin minimal komplikasyonla başarılı bir şekilde gerçekleştirilebilmesine olanak sağlayacaktır.

\section{Kaynaklar}

1. Tzelves L, Mourmouris P, Skolarikos A.Comparison of current guidelines on medical management of stone disease. Arch Esp Urol 2021;74:171-82.

2. Knoll T, Schubert AB, Fahlenkamp D, Leusmann DB, WendtNordahl G, Schubert G. Urolithiasis through the ages: data on more than 200,000 urinary stone analyses. J Urol 2011;185:1304-11.

3. Kim CH, Chung DY, Rha KH, Lee JY, Lee SH. Effectiveness of Percutaneous Nephrolithotomy, Retrograde Intrarenal Surgery, and Extracorporeal Shock Wave Lithotripsy for Treatment of Renal Stones: A Systematic Review and Meta-Analysis. Medicina (Kaunas) 2020;57:26-31.

4. Türk C, Petřík A, Sarica K, et al. EAU guidelines on interventional treatment for urolithiasis. Eur Urol 2016;69:475-482.

5. Oguz U, Resorlu B, Ozyuvali E, Bozkurt OF, Senocak C, Unsal A. Categorizing intraoperative complications of retro-grade intrarenal surgery. Urol Int 2014;92:164-168.

6. Gu XJ, Lu JL, Xu Y. Treatment of large impacted proximal ureteral stones: randomized comparison of minimally invasive percutaneous antegrade ureterolithotripsy versus retrograde ureterolithotripsy. World J Urol 2013;31:1605-10.

7. Long Q, Guo J, Xu Z, et al. Experience of mini-percutaneous nephrolithotomy in the treatment of large impacted proximal ureteral stones. Urol Int 2013;90:384-8.

8. Sun X, Xia S, Lu J, Liu H, Han B, Li W. Treatment of large impacted proximal ureteral stones: randomized comparison of percutaneous antegrade ureterolithotripsy versus retrograde ureterolithotripsy. J Endourol 2008;22:913-7.

9. Assimos D, Krambeck A, Miller NL, et al. Surgical Management of Stones: American Urological Association/Endourological Society Guideline, PART I. J Urol 2016;196:1153-60.

10. Aykac A, Baran O. Safety and efficacy of retrograde intrarenal surgery in geriatric patients by age groups. Int Urol Nephrol 2020;52:2229-2236. 
11. Gökce Mİ, Akpinar Ç, Obaid K, Süer E, Gülpinar Ö, Bedük Y. Comparison of retrograde ureterorenoscopy (URS) and percutaneous anterograde ureteroscopy for removal of impacted upper ureteral stones $>10 \mathrm{~mm}$ in the elderly population. Int Braz J Urol 2021;47:6470.

12. Gokcen K, Dundar G, Bagcioglu M, Karagoz MA, Gokce G, Sarica K. Safety and Efficacy of RIRS in Geriatric Patients: A Comparative Evaluation on an Age Based Manner. Urol J 2020;17:129-133.

13. Charlson ME, Pompei P, Ales KL, MacKenzie CR. A new method of classifying prognostic comorbidity in longitudinal studies: development and validation. J Chronic Dis 1987;40:373-83.

14. Dindo D, Demartines N, Clavien PA. Classification of surgical complications: a new proposal with evaluation in a cohort of 6336 patients and results of a survey. Ann Surg 2004;240:205-13.

15. Chatterji S, Byles J, Cutler D, Seeman T, Verdes E. Health, functioning, and disability in older adults--present status and future implications. Lancet 2015;385:563-75.

16. Giusti G, Proietti S, Cindolo L, et al. Is retrograde intrarenal surgery a viable treatment option for renal stones in patients with solitary kidney? World J Urol 2015;33:309-14

17. Prattley S, Voss J, Cheung S, Geraghty R, Jones P, Somani BK. Ureteroscopy and stone treatment in the elderly ( $\geq 70$ years): prospective outcomes over 5- years with a review of literature. Int Braz J Urol 2018;44:750-757.

18. Berardinelli F, De Francesco P, Marchioni M, et al. RIRS in the elderly: Is it feasible and safe? Int J Surg 2017;42:147-151. 